\title{
TREATMENT ADHERENCE AND SOCIAL SUPPORT AMONG WOMEN WITH SCHIZOPHRENIA
}

KEY WORDS: Treatment

Adherence, Social Support,

Women with Schizophrenia

\section{Manjunatha Shivarudraiah*}

\section{Daliboina Muralidhar}

Ph.D. Scholar in Psychiatric Social Work Department of Psychiatric Social Work, National Institute of Mental Health and Neuro Sciences, Bengaluru560029. *Corresponding Author

Retired Professor, Department of Psychiatric Social Work, National Institute of Mental Health and Neuro Sciences, Bengaluru-560029.

Introduction: Women with schizophrenia face several challenges in terms of treatment adherence and social support. Most people with schizophrenia in low- and middle-income countries like India receive minimal formal care and poor social support, which further influence high non-adherence to medication.

Methodology: The descriptive research design has been adopted, and 60-women with schizophrenia were recruited for the study from out-patient services of NIMHANS Hospital, Bengaluru. Subjects were selected by using a consecutive sampling method. The researcher used a self-prepared checklist to assess Treatment Adherence among Women with Schizophrenia (TAWS) and the Multidimensional Scale of Perceived Social Support (MSPSS) to collect the data.

Results: Adherence to treatment among women with schizophrenia has been influenced by many factors such as other family activities are getting clash with the therapy, affordability, longer duration of treatment, accessibility, side effects of medicine, social stigma, misconceptions about medicine, resistance to taking medication, negative attitude towards treatment, repeated blood investigations and complex follow-ups, etc. Social Support from Family and significant others are negatively correlated with Treatment adherence among women with Schizophrenia.

Conclusion: Poor adherence to treatment in patients with schizophrenia is a significant risk factor for poor outcomes, including relapse, re-hospitalization, and suicide. A thorough understanding of the multiple factors that influence adherence among women with schizophrenia would better deal with this problem.

\section{INTRODUCTION}

Schizophrenia is a chronic and severe mental disorder affecting twenty million people. Distortions characterize it in thinking, perception, emotions, language, sense of self, and behaviour. Everyday experiences include hallucinations hearing voices or seeing things that are not there, and delusions fixed, false beliefs (Collaborators et al., 2020). Women with schizophrenia face several challenges in terms of treatment adherence and social support. Most people with schizophrenia in low- and middle-income countries like India receive minimal formal care and poor social support, which further influence high non-adherence to medication.

Women have a better outcome than men. The madras study longitudinal study found better results in women after five years of follow-up, but this did not sustain through the rest of the 15 years of follow-up (Thara, 2004). Among the Schizophrenia population, insight into ill health could be predominantly applicable significantly when improving adherence to treatment and reducing the threat of relapse and re-hospitalization(Amador et al., 1993).

The majority of the studies conducted among persons with schizophrenia have focused mainly on the male and general population, and women-focused studies are lacking. Most of the studies are conducted in Western countries. There are no studies available from India about treatment adherence, socio-occupational functioning, and perceived social support among women with schizophrenia. Hence there is a need to determine the treatment adherence and related variables among women with schizophrenia in Indian settings.

The study findings would pave the way for specific strategies to overcome treatment adherence barriers, especially among women with schizophrenia. The various research aspectstreatment adherence, socio-occupational functioning, and perceived social support-will contribute to service delivery, training, and research implication, especially for women with schizophrenia.

\section{METHODOLOGY}

The aim of the study is to understand the socio-demographic details, social support, and the pattern of treatment adherence among women with schizophrenia. Hence, a descriptive method of research was adopted. A consecutive sampling method was used in the study. The samples of 60 respondents were recruited for this study. The study protocol was reviewed and approved by the Department Sub Ethics Committee of the National Institute of Mental Health and Neurosciences, Bengaluru, India and permission was taken from the Psychiatry Consultant of the Schizophrenia and Metabolic clinic, from where the respondents were seeking treatment. Data gathered from the respondents met the inclusion and exclusion criteria in the Schizophrenia and Metabolic clinic OPD Clinic of NIMHANS. Informed Consent Form was given and filled up by the respondents to indicate their willingness to participate in the research. If the consent form was signed, the interview proceeded conveniently to both parties, using the structured interview schedule. Discussions were held throughout 4-month. Interviews lasted between 40 and 60 minutes and were conducted in quiet settings within the hospital where there was a minimal chance of being distracted. Initially, the socio-demographic sheet was filled up, and following that, the treatment adherence checklist was administered.

Socio-demographic background sheet of the women with Schizophrenia includes age, gender, religion, education, occupation before the onset of illness, marital status; diagnosis, duration of disease and course of treatment and also the clinical variables of Clinical global impression such as CGI-severity and CGI-improvement and Scales for the assessment of positive and negative symptoms (SAPS/SANS) (Andreasen, Flaum, Swayze, Tyrrell, \& Arndt, 1990).

The researcher prepared a checklist to assess Treatment Adherence among Women with Schizophrenia (TAWS). It is a type of response category of 46 items yes or no checklist, evaluates especially women with schizophrenia-related to treatment adherence problems. Each question is 'Yes' and 'No' option score between 1 and 2. The researcher developed this checklist by following systematic steps.

a) As a first step, the researcher thoroughly reviewed the literature about schizophrenia and problems with 
treatment adherence. Both Indian and Western was literature was revived.

b) As a second step, the researcher conducted an open interview with Women among Schizophrenia patients. The essence of both the steps was discussed thoroughly with the research guide.

c) The Semi-Structured Checklist of Treatment Adherence among Women with Schizophrenia (TAWS) was prepared with items. Response categories were subjected to face and content validation by seven experts from mental health.

d) The preliminary draft was given to a group of 7 experts comprising of a psychiatrist $(n=1)$, psychiatric social workers $(n=4)$, clinical psychologist $(n=1)$, and psychiatry nursing $(n=1)$ with at least five years of experience in working with patients with schizophrenia. Therefore, the checklist's content validity was satisfactory, and the (TAWS) was ready for use in the study. Thus the final checklist contains 46 items with 'Yes' and 'No' response categories.

\section{RESULTS}

The socio-demographic information shows that the study sample consists of $100 \%$ women population. The marital status as single, married, divorced, separated, and widow ratio was $16: 36: 1: 4: 3$ with the majority $60.0 \%$ of the patients belonging to the married category. The religion of patients as Hindu, Islam, Christianity, and $87.7 \%$ of the patients followed the Hindu religion. The domicile of patients as the majority of patients hailing from rural areas $68.3 \%$ and the women's occupational status with schizophrenia patients shows that most of the patients were employed as housewives, $56.7 \%$. The results are depicted in the table- 1 .

Table 1: Sociodemographic characteristics of the respo ndents

\begin{tabular}{|l|l|c|c|}
\hline Characteristics & Frequency & Percentage \\
\hline Gender & Female & 100 & 100 \\
\hline Marital status & Single & 16 & 26.7 \\
& Married & 36 & 60.0 \\
& Divorced & 1 & 1.7 \\
& Separated & 4 & 6.7 \\
& Widow & 3 & 5.0 \\
\hline Educational & Illiterate & 17 & 28.3 \\
Status & Primary school & 17 & 28.3 \\
& Secondary school & 16 & 26.7 \\
& Graduate/college & 8 & 13.3 \\
& PG/university & 2 & 3.3 \\
\hline Religion & Hindu & 49 & 81.7 \\
& Muslim & 5 & 8.3 \\
& Christian & 6 & 10.0 \\
\hline Domicile & Rural & 41 & 68.3 \\
& Urban & 19 & 31.7 \\
\hline Occupation & Housewife & 34 & 56.7 \\
& Teacher & 1 & 1.7 \\
& Domestic help & 19 & 31.7 \\
& Business & 1 & 1.7 \\
& Professional & 1 & 1.7 \\
& Others & 4 & 6.7 \\
\hline
\end{tabular}

The result of diagnosis among women with schizophrenia as most of the patients diagnosed was Paranoid schizophrenia $76.7 \%$. In comparison, $16.7 \%$ were reported as Undifferentiated Schizophrenia, 5\% were reported as schizophrenia, and $1.7 \%$, were reported as Residual Schizophrenia. The clinical global impression among women with schizophrenia as most patients were reported severely ill $31.7 \%$.In comparison, $28.3 \%$ were reported as mild ill, $26.7 \%$ were reported as moderate ill, and the remaining $13.3 \%$ were reported as marked ill.

The Clinical global impression improvement among women with schizophrenia as the majority of the patients were minimal improved $41.7 \%$, while $40.0 \%$ were reported as much improved, $8.3 \%$ were reported as no change, $5.0 \%$ were reported as minimally worse, $3.3 \%$ were reported as very much improved, $3.3 \%$ were reported as very much worse, and remaining $1.7 \%$ were reported as much worse. The results are depicted in the table-2.

Table 2: Clinical details women with schizophrenia

\begin{tabular}{|c|c|c|c|}
\hline \multicolumn{2}{|c|}{$\begin{array}{l}\text { Clinical details Women with } \\
\text { schizophrenia }\end{array}$} & Frequency & Percentage \\
\hline Diagnosis & \begin{tabular}{|l} 
Paranoid \\
Schizophrenia \\
Schizophrenia \\
Undifferentiated \\
Schizophrenia \\
Residual \\
Schizophrenia
\end{tabular} & $\begin{array}{l}46 \\
3 \\
10 \\
1\end{array}$ & $\begin{array}{l}76.7 \\
5.0 \\
16.7 \\
1.7\end{array}$ \\
\hline $\begin{array}{l}\text { Clinical Global } \\
\text { Impression }\end{array}$ & \begin{tabular}{|l} 
Mildly Ill \\
Moderately Ill \\
Markedly Ill \\
Severely Ill
\end{tabular} & $\begin{array}{l}17 \\
16 \\
8 \\
19\end{array}$ & \begin{tabular}{|l|}
28.3 \\
26.7 \\
13.3 \\
31.7
\end{tabular} \\
\hline $\begin{array}{l}\text { Clinical Global } \\
\text { Impression } \\
\text { Improvement }\end{array}$ & $\begin{array}{l}\text { Very Much } \\
\text { Improved } \\
\text { Much Improved } \\
\text { Minimally } \\
\text { Improved } \\
\text { No Change } \\
\text { Minimally Worse } \\
\text { Much Worse } \\
\text { Very Much } \\
\text { Worse }\end{array}$ & \begin{tabular}{|l}
2 \\
24 \\
\\
25 \\
5 \\
3 \\
1 \\
2
\end{tabular} & $\begin{array}{l}3.3 \\
40.0 \\
41.7 \\
8.3 \\
5.0 \\
1.7 \\
\\
3.3\end{array}$ \\
\hline
\end{tabular}

Table: 3 Treatment Adherence of Women with Schizo phrenia Checklist

\begin{tabular}{|c|c|c|c|}
\hline \multirow{2}{*}{\begin{tabular}{|c|} 
Sl \\
No
\end{tabular}} & \multirow{2}{*}{$\begin{array}{l}\text { Treatment Adherence of Women with } \\
\text { Schizophrenia Checklist }\end{array}$} & \multicolumn{2}{|c|}{ Yes } \\
\hline & & $\mathrm{n}$ & $\%$ \\
\hline 1. & $\begin{array}{l}\text { I tend to become irritated at times not in } \\
\text { the mood to take medicines }\end{array}$ & 48 & $80.0 \%$ \\
\hline 2. & $\begin{array}{l}\text { I need to wait for a more extended period } \\
\text { for my check up's }\end{array}$ & 55 & $91.7 \%$ \\
\hline 3. & $\begin{array}{l}\text { Different doctors see me during each } \\
\text { check-up }\end{array}$ & 57 & $95.0 \%$ \\
\hline 4. & $\begin{array}{l}\text { Being a government hospital, I want free } \\
\text { treatment }\end{array}$ & 53 & $88.3 \%$ \\
\hline 5. & $\begin{array}{l}\text { I prefer to check up for my treatment at a } \\
\text { nearby place }\end{array}$ & 46 & $76.7 \%$ \\
\hline 6. & I stopped medicines as my problem solved & 43 & $71.7 \%$ \\
\hline 7. & $\begin{array}{l}\text { Mine Follow updates and timings clashes } \\
\text { with the routine activities of my family } \\
\text { members }\end{array}$ & 55 & $91.7 \%$ \\
\hline 8. & $\begin{array}{l}\text { Often physical preparation is required for } \\
\text { laboratory investigation }\end{array}$ & 54 & $90.0 \%$ \\
\hline 9. & $\begin{array}{l}\text { Traveling to the hospital for follow up visit } \\
\text { is developing and requires special efforts }\end{array}$ & 42 & $70.0 \%$ \\
\hline 10. & $\begin{array}{l}\text { The clash between the crucial events in the } \\
\text { family (marriage, childbirth, relative visits } \\
\text { or death, etc.) and the follow-up date }\end{array}$ & 54 & $90.0 \%$ \\
\hline 11. & $\begin{array}{l}\text { Sometimes medicines affect my both hand } \\
\text { shiver and movement in my neck }\end{array}$ & 48 & $80.0 \%$ \\
\hline 12. & $\begin{array}{l}\text { My family members often express anxiety } \\
\text { about change in my monthly periods while } \\
\text { on medicines }\end{array}$ & 50 & $83.3 \%$ \\
\hline 13. & $\begin{array}{l}\text { I do not know why I need to come } \\
\text { repeatedly for a checkup }\end{array}$ & 58 & $96.7 \%$ \\
\hline 14. & $\begin{array}{l}\text { We don't have a BPL card and cannot bear } \\
\text { the cost of medicines }\end{array}$ & 40 & $66.7 \%$ \\
\hline 15. & $\begin{array}{l}\text { Sometimes I forget to take regular } \\
\text { medicines }\end{array}$ & 57 & $95.0 \%$ \\
\hline 16. & $\begin{array}{l}\text { I do not know why I need to continue } \\
\text { medicines }\end{array}$ & 58 & $96.7 \%$ \\
\hline
\end{tabular}




\begin{tabular}{|c|c|c|c|}
\hline 17. & $\begin{array}{l}\text { I think I need not continue to take } \\
\text { medicines }\end{array}$ & 57 & $95.0 \%$ \\
\hline 18. & $\begin{array}{l}\text { I am putting on weight with the medicines I } \\
\text { am currently on }\end{array}$ & 50 & $83.3 \%$ \\
\hline 19. & $\begin{array}{l}\text { Different people think and enquire in } \\
\text { different ways about change in my } \\
\text { menstrual periods }\end{array}$ & 53 & $8.3 \%$ \\
\hline 20. & I want to see myself without medicines & 57 & $95.0 \%$ \\
\hline 21. & $\begin{array}{l}\text { If I continue medicines, others think that I } \\
\text { am not well }\end{array}$ & 52 & $86.7 \%$ \\
\hline 22. & $\begin{array}{l}\text { I am not satisfied with refers to medical } \\
\text { treatment }\end{array}$ & 44 & $73.3 \%$ \\
\hline 23. & $\begin{array}{l}\text { I believe that my problems will resolve by } \\
\text { themselves over time }\end{array}$ & 48 & $80.0 \%$ \\
\hline 24. & $\begin{array}{l}\text { I am taking treatment because of the } \\
\text { pressure from my family members }\end{array}$ & 53 & $88.3 \%$ \\
\hline 25. & $\begin{array}{l}\text { The medicine does not make me as active } \\
\text { as per the expectation of my family } \\
\text { members }\end{array}$ & 52 & $86.7 \%$ \\
\hline 26 & $\begin{array}{l}\text { I have difficulty comm } \\
\text { residence and the tre }\end{array}$ & 49 & $1 \%$ \\
\hline
\end{tabular}

Above the table-3 describes women's treatment adherence with the schizophrenia Checklist; this checklist consists of 46 questions. Out of 46 questions and $65 \%$ response categories, questions were shown in this table. Each question has responses of yes or no.

$80.0 \%$ of the respondents reported that they tend to become irritated at times not in mood to take medicines, $91.7 \%$ of the respondents reported that they need to wait for a longer period of time for my check up's, $95.0 \%$ of the respondents reported that they were seeing different doctors during each check up, $88.3 \%$ of the respondents reported that they want free treatment from government hospital, $76.7 \%$ of the respondents reported that they preferred check up for their treatment at a near place, $71.7 \%$ of the respondents reported that they stopped medicines as their problem solved, $91.7 \%$ of the respondents reported that their follow up dates and timings clashes with routine activities of their family members, $90.0 \%$ of the respondents reported that they Often physical preparation was required for laboratory investigation, $70.0 \%$ of the respondents reported that they travelling to hospital for follow up visit is developing and requires special efforts, $90.0 \%$ of the respondents reported that they have been clash between the important events in family such as marriage, child birth, relative visits or death etc and follow-up date, $80.0 \%$ of the respondents reported that they have been experienced sometimes medicines affect their both hand shiver and movement in their neck, $83.3 \%$ of the respondents reported that their family members often express anxiety about change in their monthly periods while on medicines, $96.7 \%$ of the respondents reported that they do not know why they need to come repeatedly for check up, $66.7 \%$ of the respondents reported that they don't have a BPL card and cannot bear the cost of medicines, $95.0 \%$ of the respondents reported that sometimes they forget to take regular medicines, $96.7 \%$ of the respondents reported that do not know why they need to continue their medicines, $95.0 \%$ of the respondents reported that they think their need not continue to take their medicines, $83.3 \%$ of the respondents reported that they putting on weight with the medicines, $88.3 \%$ of the respondents reported that different people think and enquire in different ways about change in their menstrual periods, $95.0 \%$ of the respondents reported that they want to see themselves without medicines, $86.7 \%$ of the respondents reported that if they continue medicines, others think that they not well, $73.3 \%$ of the respondents reported that they not satisfied with refers to medical treatment, $80.0 \%$ of the respondents reported that they belief that their problems will resolve by itself over time, $88.3 \%$ of the respondents reported that they taking treatment because of the pressure from their family members, $86.7 \%$ of the respondents reported that the medicine does not make their as active as per the expectation of my family members and $81.7 \%$ of the respondents reported that they have difficulty community between the residence and the treating centre.

Table-4: Comparison of Socio-demographic variables between Single and Married

\begin{tabular}{|l|c|c|c|c|}
\hline Variables & $\begin{array}{c}\text { Single } \\
(\mathrm{n}=16) \\
\text { Mean (SD) }\end{array}$ & $\begin{array}{c}\text { Married } \\
(\mathrm{n}=44) \\
\text { Mean (SD) }\end{array}$ & $\begin{array}{c}\text { U } \\
\text { Score }\end{array}$ & $\begin{array}{c}\text { P- } \\
\text { value }\end{array}$ \\
\hline Age in year & $\begin{array}{c}28.81 \\
(11.46)\end{array}$ & $42.27(10.24)$ & -3.934 & $\begin{array}{c}<0.000 \\
* *\end{array}$ \\
\hline $\begin{array}{l}\text { Age of onset in the } \\
\text { year }\end{array}$ & $\begin{array}{c}22.19 \\
(10.05)\end{array}$ & $31.59(9.34)$ & -4.026 & $\begin{array}{c}<0.000 \\
* *\end{array}$ \\
\hline $\begin{array}{l}\text { Duration of illness } \\
\text { untreated in year }\end{array}$ & $0.61(0.86)$ & $0.90(1.16)$ & -1.070 & 0.284 \\
\hline $\begin{array}{l}\text { Duration of treatment } \\
\text { in the year }\end{array}$ & $6.16(6.18)$ & $9.61(8.28)$ & -1.876 & 0.061 \\
\hline
\end{tabular}

( $\mathrm{p}$ value $\mathrm{p}<0.05, *=<0.05, * *=<0.01$ )

The results are depicted in the table-4. To test the difference between the two groups Mann-Whitney U test was used. It was found that the ages of Single and Married women with schizophrenia were significantly different, with married women with schizophrenia having significantly higher Age compared to the unmarried. ( $\mathrm{U}=-3.934, \mathrm{p}=<0.001$ ). This is statistically highly significant.

The age of onset of Single and married among women with schizophrenia significantly different from married women with schizophrenia was greater than unmarried women with schizophrenia, which was statistically significant. (U=-4.026, $\mathrm{p}=<0.001$ ).

No significant differences were found among other variables such as Duration of illness untreated and Duration of treatment concerning Single and Married among women with schizophrenia.

Table-5: Comparison of Scales for the assessment of Positive and Negative Symptoms and Treatment adherence among women with Schizophrenia checklist variables between Single and Married

\begin{tabular}{|l|c|c|c|c|}
\hline Variables & $\begin{array}{c}\text { Single } \\
(\mathrm{n}=16) \\
\text { Mean (SD) })\end{array}$ & $\begin{array}{c}\text { Married } \\
(\mathrm{n}=44) \\
\text { Mean (SD) }\end{array}$ & $\begin{array}{c}\text { U } \\
\text { Score }\end{array}$ & $\begin{array}{c}\text { P- } \\
\text { value }\end{array}$ \\
\hline $\begin{array}{l}\text { SAPS Hallucination } \\
\text { total }\end{array}$ & $5.69(8.26)$ & $7.91(8.95)$ & -1.147 & 0.251 \\
\hline SAPS Delusion total & $5.25(6.30)$ & $6.91(8.42)$ & -0.483 & 0.629 \\
\hline $\begin{array}{l}\text { SAPS Bizzare Behavior } \\
\text { total }\end{array}$ & $1.63(3.34)$ & $4.09(5.74)$ & -1.644 & 0.100 \\
\hline $\begin{array}{l}\text { SAPS Positive Formal } \\
\text { Thought Disorder total }\end{array}$ & $1.31(2.98)$ & $2.14(4.32)$ & -0.508 & 0.612 \\
\hline $\begin{array}{l}\text { SANS Affective } \\
\text { Flattening total }\end{array}$ & $2.31(5.36)$ & $3.95(5.85)$ & -1.452 & 0.146 \\
\hline SANS Alogia total & $1.81(4.32)$ & $4.36(6.10)$ & -1.588 & 0.112 \\
\hline SANS Avolition total & $1.19(3.29)$ & $2.05(3.57)$ & -1.357 & 0.175 \\
\hline SANS Anhedonia total & $1.06(4.25)$ & $3.52(4.59)$ & -2.624 & $0.009 *$ \\
\hline SANS Attention total & $0.44(1.75)$ & $2.93(4.14)$ & -2.654 & $0.008^{*}$ \\
\hline TAWS checklist & 30.43 & 33.09 & -1.281 & 0.200 \\
& $(6.88)$ & $(6.72)$ & & \\
\hline
\end{tabular}

( $p$ value $\mathrm{p}<0.05, *=<0.05, * *=<0.01$ )

The results are depicted in. The table-5, the Mann-Whitney U test was used to compare the Scales for the assessment of Positive and Negative Symptoms and Treatment adherence among women with Schizophrenia checklist variables between single and married. The Scales result for the assessment of Negative Symptoms of Anhedonia total score shows that single and married were significantly different with married women with schizophrenia patients having 
significantly higher Symptoms of Anhedonia than unmarried women with schizophrenia patients ( $\mathrm{U}=-2.624, \mathrm{p}=<0.005)$. This is statistically highly significant.

Negative Symptoms of Attention total score shows that single and married were significantly different with married women with schizophrenia patients having significantly higher Negative Symptoms of Attention total score than unmarried women with schizophrenia patients ( $\mathrm{U}=-2.654, \mathrm{p}=<0.005)$. This is statistically highly significant.

No significant differences were found between other variables such as Scales for the assessment of Positive and Negative Symptoms such as Hallucination, Delusion, Bizzare Behavior, Positive Formal Thought Disorder, Affective Flattening, Alogia, Avolition, and Treatment adherence among women with Schizophrenia checklist variables concerning single and married women with schizophrenia patients.

Table-6: Comparison of socio demographic variables between patients according to Education

\begin{tabular}{|l|c|c|c|c|c|c|}
\hline Variables & $\begin{array}{c}\text { Illiterat } \\
\text { e(n=17) } \\
\text { Mean } \\
(\mathrm{SD})\end{array}$ & $\begin{array}{c}\text { Primary } \\
(\mathrm{n}=17) \\
\text { Mean } \\
(\mathrm{SD})\end{array}$ & $\begin{array}{c}\text { Secondary } \\
(\mathrm{n}=16) \\
\text { Mean } \\
(\mathrm{SD})\end{array}$ & $\begin{array}{c}\text { Graduate } \\
(\mathrm{n}=10) \\
\text { Mean } \\
(\mathrm{SD})\end{array}$ & $\begin{array}{c}\text { Chi- } \\
\text { Square }\end{array}$ & $\begin{array}{c}\text { P } \\
\text { value }\end{array}$ \\
\hline $\begin{array}{l}\text { Age in } \\
\text { year }\end{array}$ & $\begin{array}{c}50.79 \\
(9.48)\end{array}$ & $\begin{array}{c}38.41 \\
(9.20)\end{array}$ & $\begin{array}{c}33.75 \\
(13.08)\end{array}$ & $\begin{array}{c}32.08 \\
(6.47)\end{array}$ & 19.133 & $<0.001$ \\
$* *$ \\
\hline
\end{tabular}

\begin{tabular}{|l|c|c|c|c|c|c|}
\hline $\begin{array}{l}\text { Age of } \\
\text { onset in the } \\
\text { year }\end{array}$ & $\begin{array}{c}39.71 \\
(10.00 \\
)\end{array}$ & $\begin{array}{l}28.47 \\
(8.91)\end{array}$ & $\begin{array}{c}23.38 \\
(8.86)\end{array}$ & $\begin{array}{c}25.46 \\
(4.80)\end{array}$ & 20.446 & $\begin{array}{c}<0.001 \\
* *\end{array}$ \\
\hline $\begin{array}{l}\text { Duration of } \\
\text { illness } \\
\text { untreated in } \\
\text { year }\end{array}$ & $\begin{array}{c}1.164 \\
(1.53)\end{array}$ & $\begin{array}{l}1.035 \\
(0.90)\end{array}$ & $\begin{array}{l}0.638 \\
(0.97)\end{array}$ & $\begin{array}{c}0.415 \\
(0.7504)\end{array}$ & 7.261 & 0.064 \\
\hline $\begin{array}{l}\text { Duration of } \\
\text { treatment in } \\
\text { the year }\end{array}$ & 9.30 & 9.04 & $9.65(9.36)$ & $\begin{array}{c}6.13 \\
(7.16)\end{array}$ & 0.679 & 0.878 \\
\hline
\end{tabular}

( $p$ value $\mathrm{p}<0.05, *=<0.05, * *=<0.01$ )

The results are depicted in the table-6, to test the difference among the four groups; Kruskal-Wallis Test was used. It was found that the age of women with schizophrenia patients education were significantly differing with the illiterate of women with schizophrenia patients having a significantly higher age compared to other qualification such as primary, secondary, graduate of women with schizophrenia patients, $\left(X^{2}=19.133\right.$, $\mathrm{p}=<0.001)$ This is statistically highly significant.

The age of onset of respondents' education significantly differed with the illiterate of women with schizophrenia patients having a significantly higher age of onset than other qualifications such as primary, secondary, and graduate of women with schizophrenia patients $\left(X^{2}\right.$ $=20.446, p=<0.001)$. This is statistically highly significant, and no significant differences were found among other variables.

Table-7: Comparison of Scales for the assessment of Positive and Negative Symptoms and Treatment adherence among women with Schizophrenia checklist patients according to education

\begin{tabular}{|c|c|c|c|c|c|c|}
\hline Variables & $\begin{array}{c}\text { Illiterate } \\
(n=17) \\
\text { Mean (SD) }\end{array}$ & $\begin{array}{c}\text { Primary } \\
(n=17) \\
\text { Mean (SD) }\end{array}$ & \begin{tabular}{|c|} 
Secondary \\
$(\mathrm{n}=16)$ Mean \\
(SD)
\end{tabular} & $\begin{array}{c}\text { Graduate } \\
(n=10) \\
\text { Mean (SD) }\end{array}$ & Chi-Square & $\begin{array}{c}\mathrm{P}- \\
\text { value }\end{array}$ \\
\hline SAPS Hallucination total & $8.86(9.41)$ & $9.18(8.92)$ & $7.13(8.47)$ & $3.46(7.83)$ & 4.880 & 0.181 \\
\hline SAPS Delusion total & $7.57(8.08)$ & $8.35(8.71)$ & $6.00(6.79)$ & $3.38(7.73)$ & 5.404 & 0.144 \\
\hline SAPS Bizzare Behavior total & $3.36(5.42)$ & $5.06(5.88)$ & $1.31(2.46)$ & $4.00(6.50)$ & 4.586 & 0.205 \\
\hline SAPS Positive Formal Thought Disorder total & $2.36(3.87)$ & $2.53(4.57)$ & $1.94(4.65)$ & $0.62(2.21)$ & 2.419 & 0.490 \\
\hline SANS Affective Flattening total & $5.07(6.30)$ & $4.47(6.67)$ & $3.38(5.78)$ & $0.77(2.24)$ & 4.987 & 0.173 \\
\hline SANS Alogia total & $3.71(4.63)$ & $5.29(7.41)$ & $3.13(4.51)$ & $2.23(5.89)$ & 3.035 & 0.386 \\
\hline SANS Avolition total & $2.50(3.91)$ & $2.94(4.40)$ & $0.81(2.56)$ & $0.85(2.15)$ & 5.924 & 0.115 \\
\hline SANS Anhedonia total & $3.29(4.96)$ & $3.59(4.87)$ & $1.94(3.33)$ & $2.62(5.45)$ & 1.699 & 0.637 \\
\hline SANS Attention total & $2.86(3.30)$ & $3.35(4.78)$ & $1.44(3.07)$ & $1.23(3.63)$ & 5.003 & 0.172 \\
\hline TAWS checklist & $29.78(7.10)$ & $29.58(7.05)$ & $34.68(4.61)$ & $36.00(6.35)$ & 9.516 & $0.023 *$ \\
\hline
\end{tabular}

( $\mathrm{p}$ value $\mathrm{p}<0.05, *=<0.05, * *=<0.01)$

The results are depicted in the table-7, to test the difference among the four groups; Kruskal-Wallis Test was used. It was found that Treatment adherence among women with Schizophrenia checklist education was significantly differing with the illiterate of women with schizophrenia patients having a significantly higher treatment adherence compared to other qualification such as primary, secondary, graduate of women with schizophrenia patients $\left(X^{2}=9.516\right.$, $\mathrm{p}=<0.005$ ) and No significant differences were found among other variables such as Scales for the assessment of Positive symptoms and Scales for the assessment of Negative Symptoms.

Table-8: Relationship between TASW and independent variables

\begin{tabular}{|c|c|c|c|c|c|c|c|c|c|c|c|c|c|c|c|c|c|c|}
\hline $\begin{array}{c}\text { Variable } \\
\text { s }\end{array}$ & $\begin{array}{c}\mathrm{CGI} \\
\mathrm{S}\end{array}$ & CGI_SI & Age & Aoo & Doiu & Dot & $\begin{array}{c}\text { SAPS_ } \\
\text { H_Tot } \\
\text { al }\end{array}$ & $\begin{array}{c}\text { SAPS } \\
\text { D_Tota } \\
1\end{array}$ & $\begin{array}{c}\text { SAPS } \\
\text { BB_Tot } \\
\text { al }\end{array}$ & $\begin{array}{c}\text { SAPS } \\
\text { PFT_T } \\
\text { otal }\end{array}$ & $\mid \begin{array}{c}\text { SANS_ } \\
\text { AF_To } \\
\text { tal }\end{array}$ & {$\left[\begin{array}{c}\text { SANS } \\
\text { A_Tot } \\
\text { al }\end{array}\right.$} & $\begin{array}{c}\text { SANS } \\
\text { Aa }\end{array}$ & $\begin{array}{c}\text { SANS } \\
\mathrm{Aa}\end{array}$ & $\begin{array}{c}\text { SANS- } \\
\bar{A}\end{array}$ & $\begin{array}{c}\text { SS } \\
\text { Social }\end{array}$ & $\begin{array}{c}\text { SS_Fri } \\
\text { ends }\end{array}$ & $\begin{array}{c}\text { SS_Fa } \\
\text { mily }\end{array}$ \\
\hline ASW & $\begin{array}{c}-.23 \\
1\end{array}$ & -.033 & .024 & \begin{tabular}{|c|}
.07 \\
1
\end{tabular} & \begin{tabular}{|l|}
-.044 \\
\end{tabular} & $\begin{array}{c}-.03 \\
5\end{array}$ & -.113 & -.157 & \begin{tabular}{|l|}
-192 \\
\end{tabular} & -.120 & $-.304^{*}$ & $-.297^{*}$ & $-.285^{*}$ & -.236 & -.229 & $-.337^{* *}$ & $-.350^{*}$ & -.080 \\
\hline
\end{tabular}

**. Correlation is significant at the 0.01 level (2-tailed). *. Correlation is significant at the 0.05 level (2-tailed).

The above table- 8 describe the correlation of independent variables such as Affective Flattening total score domain of SANS negatively correlated with Treatment adherence among women with Schizophrenia checklist ( $r=-.304$, $\mathrm{p}<0.05)$, Alogia entire score domain of SANS is negatively correlated with Treatment adherence among women with Schizophrenia checklist $(r=-.297, \mathrm{p}<0.05)$ and Avolition total score domain of SANS is negatively correlated with Treatment adherence among women with Schizophrenia checklist $(r=-$ $.285, \mathrm{p}<0.05)$.
Multidimensional Scale of Perceived Social Support domains of Social support from Significant others is negatively correlated with Treatment adherence among women with Schizophrenia checklist $(\mathrm{r}=-.337, \mathrm{p}<0.01)$ and Multidime nsional Scale of Perceived Social Support domains of Social Support from Family is negatively correlated with Treatment adherence among women with Schizophrenia checklist $(r=-$ $.350, \mathrm{p}<0.01)$,

\section{DISCUSSION}

The study highlighted that sample consists of 60 women with schizophrenia who are recruited at NIMHANS hospital. The occurrence of schizophrenia seems to be relatively stable in 
both genders across reported studies, and madras's research on a people of 100000 did not show any gender differences (Rajkumar, Padmavathi,Thara, \& Menon, 1993).

The present study included a majority of $60.0 \%$ of the patients belonging to the married category. In counties like India, marriage is not just a social functioning marker but is almost a compulsory event in life. A similar study found a significant comparison in early course among males and females with the first episode of schizophrenia disorder. Females were more often married or lived with their spouse and kids (Segarra et al.,2012). And the results of the religion of patients as Hindu, Islam, Christianity, with a majority of $87.7 \%$ of the patients followed the Hindu religion. Because in India, we can see the majority of the population belongs to the Hindu religion. The results of patients' domicile as the majority of patients hailing from rural areas $68.3 \%$, In the Chandigarh study, the occurrence rates of mainly defined schizophrenia were the maximum among rural women $0.47 / 1000$ and lowest in urban males $0.37 / 1000$.

The present study shows that diagnosis among women with schizophrenia as most of the patients diagnosed was Paranoid schizophrenia $76.7 \%$. It has been documented that women with schizophrenia had more paranoid schizophrenia. A large sample of Chinese patients with schizophrenia had more paranoid schizophrenia in females (Usall, Suarez, Haro, \& Group, 2007). Other studies described by (Gandhi et al., 2014 ) Thirteen $21.7 \%$ of patients diagnosed be schizophrenia. The clinical global impression among women with schizophrenia as most of the patients was reported severely ill $31.7 \%$, and the distribution of Clinical global impression improvement among women with schizophrenia as the majority of the patients was minimal improved $41.7 \%$. Another study described the significance of gender in the treatment of schizophrenia. In men and women, a significant decrease in the CGI-S score $P<.001$ and The improvements in CGI-S scores were comparable in both groups, with no significant difference between men and women patients (Ceskova \& Prikryl, 2012).

The present study shows that the age of Single and Married women with schizophrenia was significantly differing, with married women with schizophrenia having significantly higher Age compared to the unmarried. The age of women with schizophrenia patients' education significantly differed with the illiterate of women with schizophrenia patients having a significantly higher age than other primary, secondary, and graduate of women with schizophrenia patients. The study on Medication adherence in schizophrenia: a comparison between outpatients and relapse cases. The mean age of inpatients and outpatients was 33 , 10 years, and 33, 8 years. More than half were male, $57 \%$, respectively, and more than half of the participants in both groups were male. The study was shown no statistical differences between the men and women groups in terms of age, gender, education level, marital status, occupation, and individual income (Razali \&Yusoff, 2014)

The present study shows that the Age of onset of Single and married women with schizophrenia significantly different from single women with schizophrenia was greater than married women with schizophrenia, which was statistically significant. A similar study shows that women subjects had a significantly $\mathrm{P}=0.035$ advanced risk of developing schizo phrenia at younger ages example, lower survival rates (Murthy,Janakiramaiah, Gangadhar, \& Subbakrishna, 1998).

The results of the Scales for the assessment of Negative Symptoms of Anhedonia total score shows that single and married were significantly differing with married women with schizophrenia patients having significantly higher Symptoms of Anhedonia compared to single women with schizophrenia patients and Negative Symptoms of Attention total score shows that single and married were significantly differing with married women with schizophrenia patients having significantly higher in Negative Symptoms of Attention total score compared to single women with schizophrenia patients. Higher mean age at onset of schizophrenia for women has been one of the very consistent findings in the last 25 years. The age of onset of respondents' education significantly differed with the illiterate of women with schizophrenia patients having a significantly higher age of onset than other qualifications such as primary, secondary, and graduate of women with schizophrenia patients. Also, treatment adherence among women with Schizophrenia checklist education significantly differed with the illiterate of women with schizophrenia patients having a significantly higher treatment adherence than other qualifications such as primary, secondary, and graduate of women with schizophrenia patients. Women have a better outcome than men. It was undecided whether this is due to later age of onset, protective nature of hormones such as improved drug response (Chandra et al., 2009)

\section{LIMITATIONS}

A low sample size of only 60 among women with schizophrenia has taken for the study due to the time limit. A more in-depth interview among women with schizophrenia, the smaller sample may have enriched the information obtained.

\section{CONCLUSION}

Adherence to treatment among women with schizophrenia has been influenced by many factors such as they tend to become irritated at times not in the mood to take medicines, seeing different doctors during each checkup, other family activities are getting clash with the treatment, affordability, longer duration of treatment, accessibility, side effects of medicine, social stigma, misconceptions about medicine, resistance to take medication, negative attitude towards treatment, repeated blood investigations and complex followups, etc. Social Support from Family and significant others are negatively correlated with Treatment adherence among women with Schizophrenia.

Schizophrenia in men and women has the same diagnostic criteria (DSM schizophrenia criteria), but differences are known between them. Lack of adherence to treatment in patients with schizophrenia is a significant risk factor for poor outcomes, including relapse, rehospitalization, and suicide. Social workers should plan for a holistic among women with schizophrenia. Poor adherence to treatment in patients with schizophrenia is a major risk factor for poor outcomes, including relapse, re-hospitalization, and suicide. A thorough understanding of the multiple factors that influence adherence among women with schizophrenia would help us deal with this problem better. The findings would enable the social work professional to effectively design the intervention programs to improve Psycho-Social correlations of Treatment Adherence amongWomen with Schizophrenia.

\section{REFERENCES}

1. Amador,X.F., Strauss, D. H.,Yale, S. A., Flaum, M. M., Endicott,J., \& Gorman,J.M. (1993). Assessment of insight in psychosis.AmJPsychiatry, $150(6), 873-879$.

2. Andreasen, N. C., Flaum, M., Swayze, V. W., Tyrrell, G., \& Arndt, S. (1990) Positive and negative symptoms in schizophrenia: A critical reappraisal. Archives of General Psychiatry, 47(7), 615-621.

3. Ceskova, E., \& Prikryl, R. (2012). Importance of gender in the treatment of schizophrenia. The primary care companion for CNS disorders, 14(6).

4. Chandra, P. S., Herrman, H., Fisher, J., Kastrup, M., Niaz, U., Rondon, M., \& Okasha, A. (2009). Contemporary Topics in Women's Mental Health. Global Perspectives in a Changing Society. Chichester:JohnWiley \& Sons Ltd.

5. Collaborators, G. B. D. O. D., Bernabe, E., Marcenes, W., Hernandez, C. R. Bailey, J., Abreu, L. G., . . A Arefi, Z. (2020). Global, regional, and national levels and trends in burden of oral conditions from 1990 to 2017: a systematic analysis for the global burden of disease 2017 study. Journal of dental research, 99(4), 362-373.

6. Gandhi, S., Pavalur, R., Thanapal, S., Parathasarathy, N. B., Desai, G., Bhola, P., Chaturvedi, S. K. (2014). Medication Adherence, Work Performance and SelfEsteem among Psychiatric Patients Attending Psychosocial Rehabilitation Services at Bangalore, India. Indian J Psychol Med, 36(4), 392-396. doi: 10.4103/0253-7176.140724 
7. Murthy, G., Janakiramaiah, N., Gangadhar, B., \& Subbakrishna, D. (1998). Sex difference in age at onset of schizophrenia: discrepant findings from India. Acta Psychiatrica Scandinavica, 97(5), 321-325.

8. Rajkumar, S., Padmavathi, R., Thara, R., \& Menon, M. S. (1993). Incidence of schizophrenia in an urban community in Madras. Indian journal of psychiatry, 35(1), 18.

9. Razali, S. M., \& Yusoff, M. Z. (2014). Medication adherence in schizophrenia: a comparison between outpatients and relapse cases. East Asian Arch Psychiatry, 24(2), 68-74.

10. Segarra, R., Ojeda, N., Zabala, A., García, J., Catalán, A., Eguíluz, J. I., \& Gutiérrez, M. (2012). Similarities in early course among men and women with a first episode of schizophrenia and schizophreniform disorder. European archives of psychiatry and clinical neuroscience, 262(2), 95-105.

11. Thara, R. (2004). Twenty-year course of schizophrenia: the Madras Longitudinal Study. Canadian Journal of Psychiatry, 49, 564-569.

12. Usall, J., Suarez, D., Haro, J. M., \& Group, S. S. (2007). Gender differences in response to antipsychotic treatment in outpatients with schizophrenia. Psychiatry research, 153(3), 225-231. 